\title{
Introduction to Aging and Caregiving in Chinese Populations
}

\author{
Jeanne Shea ${ }^{1} \cdot$ Hong Zhang ${ }^{2}$
}

Published online: 7 December 2016

(C) Springer Science+Business Media New York 2016

In this special issue, we bring together articles that explore issues related to ageing and caregiving in contemporary Chinese populations at scales ranging from a national to a community level. The seeds for this collection were sowed at the 2013 meeting of the Association for Asian Studies at which several of the contributors presented papers in a panel on Aging and Caregiving in China which we co-organized. Following the panel, we sought related material from additional researchers, forming the present array of six articles and ten contributors.

Aging and caregiving and their intersections have long been important topics in Chinese populations. In part, this is due to the emphasis that Chinese cultural traditions have placed on the Confucian ideal of respect for the elderly, filial piety toward older family members, and an old age free of want. Over the past several decades, such traditional values and the worlds they represented have come into tension with other ways of being in relation to later life. As a result, whether in China proper or in diaspora, there is a poignant tension surrounding issues of aging and caregiving in modern times, animated by both high ideals and steep challenges for attempts to realize those ideals in contemporary contexts.

As a whole, these articles all deal with issues of population aging, modernization, marketization, globalization, and changing and contested social expectations with regard to familial support of the elderly and caregiving of and by the elderly in contemporary Chinese populations. All of the articles, in one way or another, deal with the attenuation of intergenerational ties and filial obligations of adult children to their elderly parents based on changing societal age structure, social values, political/

Jeanne Shea

Jeanne.Shea@uvm.edu

Hong Zhang

Hzhang@colby.edu

1 Department of Anthropology, College of Arts and Sciences, University of Vermont, Burlington, VT, USA

2 Department of East Asian Studies, Colby College, Waterville, ME, USA 
economic circumstances, and/or social context, and the ways in which Chinese families and communities are adapting to these changes. Many of the articles describe older adults' concerns about their future care and support and point to the increasing need to turn to supplemental and alternative forms of eldercare, including spousal care, community-based care, neighborhood senior volunteerism, community eldercare workers, and converting housing holdings into long term care. While harmony in family and society is an expressed goal of the Chinese government in line with traditional Confucian values, a focus on real-life tensions within families and/or between family members and community-based helpers is present in many of the articles.

Below we discuss each of the articles in turn, starting with demographic material from the national level in China, moving to methodological issues concerning needs determination among Chinese seniors, and proceeding to aging and caregiving issues in various community-level contexts. While the demographic article provides a comparison of rural and urban areas of China, the remainder focus on the situation in urban Chinese settings, with the community-based articles situated in Shanghai and in Boston, both cities on the vanguard of Chinese population aging. Thematically, the articles bring together the subjects of aging and caregiving in several different ways. Two of them focus in various ways on caregiving for the elderly by younger family members, including: a demographic analysis of support for elders by adult children (Lafave) and a mixed methods analysis of mistreatment and neglect of elders by younger family members (Zhang). Three articles examine community-based caregiving for the elderly by non-kin, with one exploring methodological complexities of community-based assessment of seniors' needs (Chen and Levkoff), a second providing an ethnographic account of caring visits to aged neighbors provided by senior community volunteers (Shea), and a third analyzing qualitative data on professional identity among communitybased eldercare workers (Chen, Yang, Song, and Wang). Finally, one of the articles provides ethnographic insights on caregiving for younger family members done by seniors hoping to build credit in case they themselves need future care (Newendorp). Of the above articles, two deal with migration, aging, and caregiving, one in the context of internal migration in China (LaFave) and the other in relation to international migration from China to America (Newendorp).

The first piece, written by economist Daniel LaFave, examines the relationship between family support and elderly well-being in China at a national level through a quantitative analysis of large-scale multi-sited data from the China Health and Retirement Longitudinal Study (CHARLS). Using nationally-representative data, Dr. LaFave examines different modes of eldercare common in rural versus urban areas in the market reform era and the effects of internal migration on filial support for elderly parents. The analysis sheds light on the effects of demographic change, economic growth, and changing social norms regarding intergenerational transfers and support on the well-being of older adults in China today.

The second piece, contributed by psychiatry professor Hongtu Chen and behavioral scientist Sue Levkoff, reflects upon the complexity of answering the question of what urban Chinese elders today really need in terms of support, services, and care. What initially seems like a simple empirical question turns out to be difficult to answer, with 
different qualitative and quantitative methodologies often yielding somewhat different impressions. Drs. Chen and Levkoff focus on various challenges associated with relying on interview methods to evaluate the needs of home-dwelling older adults and their family caregivers. They offer tips on maximizing effectiveness in generating and using interview data for needs assessment, especially in the context of communities in China and other developing countries.

The third article by anthropology Ph.D. candidate Ms. Yan Zhang typifies various forms of elder mistreatment in reform-era urban China and their relation to emerging patterns of family-based eldercare and broader social determinants, with a special emphasis on the role of housing markets. Drawing on a community-based survey and ethnographic field research in Shanghai, Ms. Zhang argues that the three main modalities for eldercare in Shanghai today include: spousal care, traditional care by adult children, and trading real estate for long term care. She identifies three main forms of elder mistreatment in urban China today, including: intergenerational conflict and elder neglect, care by adult children made instrumentally contingent on (often premature) inheritance of housing, and structural mistreatment of elders. She traces elder mistreatment in Shanghai today to three driving factors, including: privatization of housing ownership, societal focus on economic gain, and younger generations valuing materialism and individualism over filial reciprocity.

The fourth article by anthropology professor Nicole Newendorp explores how contemporary notions concerning the "value" that seniors add to their families play an important role in shaping the caregiving contributions that Chinese senior migrants make to their extended families abroad. She also demonstrates how these concepts of senior "value" animate the conflicts that emerge when Chinese seniors migrate to the U.S. to care for younger kin. Based on ethnographic research, Dr. Newendorp shows how older Chinese migrants in the Boston area often migrate mainly to demonstrate their value to their families through caregiving for the younger generations in the hopes that their families will care about and for them in their later years. She then provides rich case illustrations of how various kinds of family conflict arise as senior Chinese migrants negotiate the terms of intergenerational respect and reciprocity in their families in diaspora.

Special issue co-editor and anthropology professor Jeanne Shea's piece brings together gerontological attention to productive aging and social support for the aged in an ethnographic analysis of innovative community-based senior volunteer efforts supporting aging in place in Shanghai. She argues that while such phenomena have received little scholarly attention thus far, Chinese older adult volunteers bring several distinctive strengths to community volunteering in support of their aged neighbors. Likewise, their service to older community members brings certain age-marked benefits back to them as volunteers, resulting in high levels of volunteer motivation and satisfaction. Overall, the article illustrates how matching senior volunteers with older neighbors in need of social support is showing excellent potential in Shanghai, although there are also some emerging challenges that need to be negotiated.

The sixth and final piece, co-authored by professor of social work Honglin Chen, professor of sociology Hui Yang, professor of anthropology Priscilla Song, and master's candidate in social work Lu Wang, examines the identities of community-based eldercare workers in urban China, exploring ambiguities in their sense of professional identity. Drs. Chen, Yang, and Song, and Ms. Wang point out how institutional placement of seniors is very rare in China, and community eldercare workers form 
the main supplement to family-based eldercare, and yet there are still very few studies of their contributions. Based on in-depth interviews and focus group discussions with community eldercare workers, the authors assist in the broader project of filling this gap. They find that for a variety of reasons these workers are often confused about the parameters of their jobs and their sense of professional identity, adding to dissatisfaction with their working conditions. The authors provide suggestions for improving the work experiences and professionalization of community eldercare workers and the urban long-term care system more broadly.

This collection of articles takes a multidisciplinary approach to investigate a number of important demographic, methodological, and ethnographic dimensions of aging and caregiving in some portions of the world's vast aging Chinese population. The overall implication of these articles is that more policy and research attention should be paid to the interaction of familial and non-familial forms of care in Chinese populations. This includes the interactions between the conditions for familial support for the elderly and the role of various forms of elder self-care, senior mutual aid, neighborhood senior volunteering, employer or government-supplied social welfare, and market-based paid community care workers. Still very rare and non-preferred by most Chinese seniors and their families, institutional care remains a very small piece of the picture. Further research is needed on aging and caregiving in additional Chinese populations over time, with a focus on various forms of non-institutional care in both urban and rural areas of China and in Chinese populations abroad. As the old-age population ratio increases up into the middle of this century as the effects of the now-defunct singlechild policy work their way through the demographic pipeline, such research will only become more important with time.

\section{Compliance with Ethical Standards}

Conflict of Interest The authors declare no conflict of interest.

Informed Consent As there is no person or personal data appearing in the paper, there is no one from whom a permission should be obtained in order to publish personal data.

Ethical Treatment of Experimental Subjects (Animal and Human) This article does not contain any studies with human or animal subjects performed by any of the authors.

Jeanne Shea is Associate Professor of Anthropology at the University of Vermont (UVM) in Burlington, Vermont in the United States. Dr. Shea has research affiliations with the Center on Aging at UVM, the Medical Anthropology Research Collaborative at Fudan University in Shanghai, and the Global Initiative on Caregiving for the Elderly at Harvard University in Boston. She completed her M.A. and Ph.D. in Anthropology at Harvard University and earned her B.A. in Asian Studies at Dartmouth College. Her research on aging in China has examined menopause and midlife aging, marital relationships, sex in later life, familial and spousal caregiving, senior volunteering, and community-based social supports for aging in place. Dr. Shea is the recipient of many grants, including two Fulbright Awards. Beyond articles in Ageing International, her agingrelated research has appeared many other journals such as the American Journal of Human Biology; Anthropology and Aging; Anthropology and Medicine; Climacteric; the China Journal; Culture, Medicine and Psychiatry; the Journal of Aging and Social Policy; Journal of Guangxi University for Nationalities; Maturitas; and Modern China. A recent book chapter on her ethnographic research on menopause appeared in Transitions and Transformations: Cultural Perspectives on Aging and the Life Course (Lynch and Danely, eds., 2015). 
Hong Zhang is Associate Professor of East Asian Studies at Colby College in Waterville, Maine, in the United States. Prior to teaching at Colby, she completed a Postdoc at the Fairbanks Center for East Asian Studies at Harvard University, an M.A., M. Phil., and Ph.D. in Anthropology at Columbia University, an M.A. in English at Wuhan University, and a B.A. in English at Huazhong Normal University. Dr. Zhang's research interests include: family and marriage, effects of the one-child policy, intergenerational relations, population aging, parental old-age support, gender, urbanization, rural-urban migration, and social change in contemporary Chinese society. Dr. Zhang is the recipient of many research grants, including a Fulbright Senior Scholar Research Award and Freeman Foundation grants. Dr. Zhang has published in numerous edited volumes, including a recent chapter on realigning state, family and market interests in relation to filial piety in the forthcoming edited volume Transformation of Chinese Patriarchy (Harrell and Santos, eds.) and a chapter on decline in family care for the elderly in China in Cultural Context of Aging: Worldwide Perspectives (Sokolovsky, ed., 2009), among others. Her research has also appeared in a wide range of journals such as the Journal of Contemporary China, the China Quarterly, Signs, the Journal of Long Term Home Care, the China Journal, and Asian Anthropology. 